\title{
A possible case of an ossifying fibroma in a Late Neolithic population from
}

\section{Portugal}

Silva, A. M.* and Wasterlain, S. N.

Centro de Investigação em Antropologia e Saúde, Department of Anthropology University of Coimbra, 3000 - 056 Coimbra, Portugal

Short title: Ossifying fibroma in Late Neolithic

*Correspondence to: Ana Maria Silva, Departamento de Antropologia, Universidade de Coimbra, 3000-056 Coimbra, Portugal

Telephone: $351239829051 \quad$ Fax: 351239823491

E-mail address: amgsilva@antrop.uc.pt 


\begin{abstract}
This paper discusses the differential diagnosis of an unusual bone tumour observed in the right maxilla of one adult calvarium, from the Late Neolithic collective burial of Lapa do Bugio (Sesimbra, Portugal). The differential diagnosis of the lesion gave rise to several possible pathological conditions, namely, ossifying fibroma, fibrous dysplasia, and focal cemento-osseous dysplasia. Despite the impossibility of performing histological analysis, various macroscopic and radiological aspects lead us to consider ossifying fibroma as the most probable diagnose. This appears to be the earliest reported case of this condition in the osteoarchaeological literature, and adds to the very few palaeopathological case descriptions available for ossifying fibroma.
\end{abstract}

Key words: Cemento-ossifying fibroma; fibro-osseous lesions; benign tumour; Late Neolithic; Portugal.

\title{
Case Report
}

The remains under analysis were recovered from the natural cave of Lapa do Bugio (Sesimbra, Portugal), which dates from the Late Neolithic period. One incomplete adult calvarium contains a bony overgrowth in the molar-bearing area of the right maxilla. The exuberant nature and rareness of the lesion as well as the scarcity of reports in the palaeopathological literature, led us to make the differential diagnosis, which we report in this paper. 


\section{$\underline{\text { Archaeological background }}$}

Lapa do Bugio is a small natural cave (long axis of $9 \mathrm{~m}$; maximum width of 5.5 m), located in a limestone cliff, in Azóia, Sesimbra (around $40 \mathrm{~km}$ south of Lisbon), hanging over the sea. The cave was discovered in 1957 by Rafael Monteiro, and first reported in 1959 by Monteiro and Cunha Serrão (Monteiro and Serrão, 1959). Several archaeological excavations took place between the late 1950's and the 1960's. The archaeological deposits inside the cave were found to be very disturbed due to human and animal activity both in ancient and modern times (Isidoro, 1964; Monteiro et al., 1971).

All the human remains recovered up to 1962 were found to be very fragmentary, commingled, and without any anatomical connection. Nowadays, these are curated in the Museu Municipal de Sesimbra and in the Museu de História Natural of the University of Porto. In the 1967 excavation, ten primary burials and an ossuary were found (Monteiro et al., 1971). However, until now it has not been possible to locate these last human remains. Radiocarbon dating of coal samples from this last burial level indicates a date of $4850 \pm 45 \mathrm{BP}$, calibrated 2 sigma (68\%): $3710-3620 \mathrm{BC}$ (Grn5628) (Monteiro et al., 1971; Cardoso, 1992).

In 1998, the human remains housed in the Museu Municipal de Sesimbra were analysed by one of the authors (AMS). The minimum number of individuals obtained was 16 (15 adults and one non-adult), based on the mandible fragments.

The individual 
The calvarium here described was found among the commingled human remains recovered between 1960 and 1962. It was first described in 1964 by Isidoro. Unfortunately, some parts of the skull 2 - MS (the temporal bones and a small part of the left side of the occipital bone) seem to have been lost since the first description. Also, the pathological lesion here reported was not identified in this earlier study. The cranium 2-MS belongs to an adult individual, probably male (Isidoro, 1964; Silva, 2002). Age was assessed as about 30-45 years, based on the state of suture closure (Masset, 1982).

\section{$\underline{\text { State of preservation }}$}

Although the maxillary bones were fairly well preserved, several teeth were lost post-mortem. The only exceptions correspond to the left central incisor, the left first molar, and both second molars, which were lost ante-mortem.

\section{Oral pathology}

There was interproximal crestal cortical bone loss, exposing the underlying porous cancellous bone, which suggests periodontal disease (Kerr, 1988, 1989; Clarke and Hirsch, 1991; Hillson, 1996).

A hollow bony lesion $10 \mathrm{~mm}$ wide and $8 \mathrm{~mm}$ high was found in relation to the left first premolar socket. The interior bony walls of the cavity are well demarcated, smooth and rounded. There is no perforation into the maxillary air sinus. Although the corresponding tooth was not present, all of the reported signs suggested a chronic dental apical lesion, most probably a periodontal cyst (Dias and Tayles, 1997; Dias et al., 2007). 
Another apical lesion was present in relation to the left first molar socket (lost post-mortem). There is perforation into the maxillary air sinus, measuring $3 \mathrm{X} 4 \mathrm{~mm}$. The appearance of the bony margins does not suggest a destructive bone lesion caused by a malignant tumour or by an infective process, but a slow-growing benign lesion (Dias and Tayles, 1997; Dias et al., 2007).

\section{Description of the condition}

A round tumour mass measuring approximately $24 \times 24 \mathrm{~mm}$ was found in the molar-bearing area of the right maxilla (Figure 1). It had completely invaded the right maxillary sinus (Figures 2 and 3). Despite its hard and osseous consistency, the tumour presented an opening on its mesial surface (Figure 4). Laterally, it had communication with the empty socket of the first right maxillary molar.

In contrast to the outer surface of the tumour, which was relatively smooth, the inner surface was much rougher and irregular, presenting several osseous outgrowths. The lesion was surrounded by furrows, most probably left by blood vessels or nerves which were diverted by the pathological outgrowth.

The visual examination of the outer surface of the right maxillary bone, showed a depression located at the same level of the tumour with associated porosity (Figure 2). A similar, but smaller depression was also visible in the same region of the left maxillary bone. No other pathological changes were seen in the left maxilla.

\section{$\underline{\text { Radiological features }}$}

The radiographic examination of the maxilla showed a well-demarcated radiolucent lesion, with internal radiopaque calcified patches (Figure 5). 
The specimens' antiquity and decomposition hampered histopathological analysis.

\section{Discussion}

The differential diagnosis of the lesion gave rise to several possible pathological conditions; namely, ossifying fibroma, fibrous dysplasia, and focal cemento-osseous dysplasia.

\section{Fibro-osseous lesions}

Fibro-osseous lesions are a poorly defined group of disorders characterized by the replacement of bone by cellular fibrous tissue containing foci of mineralization that vary in amount and appearance (MacDonald-Jankowski, 2004; Speight and Carlos, 2006).

From the fibro-osseous lesions affecting the face and jaws (osseous dysplasia, fibrous dysplasia and ossifying fibroma), the most likely diagnosis is ossifying fibroma.

\section{Ossifying fibroma}

The ossifying fibroma (OF), previously called cementifing fibroma and cementoossifying fibroma, is probably the most frequent fibro-osseous lesion seen by oral pathologists (Zupi et al., 2000). It is a benign neoplasm of the bone-forming tissues (Speight and Carlos, 2006; Regezi et al., 2000), which is described as a welldemarcated lesion, occasionally encapsulated, composed of fibrous tissue containing varying amounts of bony trabeculae and rounded calcified bodies (Soames and 
Southam, 2005; Whaites, 2007). Its demarcated nature is an important feature; distinguishing it from fibrous dysplasia (Soames and Southam, 2005).

Clinically this lesion is slow-growing and has a predilection for the pre-molarmolar region of the jaws (Regezi et al., 2000; Soames and Southam, 2005). Although found predominantly in the mandible (around 70 per cent), ossifying fibromas may arise within the paranasal sinus and the base of the skull (Shafer et al., 1983; Commins et al., 1998; Barberi et al., 2003). It can occur over a wide age range but it is more common between the second and fourth decades. Females seem to be more frequently affected than males (2:1) (Speight and Carlos, 2006; Regezi et al., 2000; Soames and Southam, 2005; Commins et al., 1998). The lesion can remain inactive for long periods of time or evolve in spurts (Colard et al., 2008). Occasionally it may produce large (up to $5 \mathrm{~cm}$ ) masses of osteolytic bone, that expand and thin the cortex (Aufderheide and RodríguezMartín, 1998), causing serious cosmetic and functional problems (Zupi et al., 2000; Barberi et al., 2003; Su et al., 1997a). Since this tumour is generally asymptomatic, it may be present for some years before discovery; swelling of the face and displacement of teeth are early clinical features (Shafer et al., 1983; Barberi et al., 2003). Tumours within the mandible tend to behave in a more indolent way in comparison to those in the paranasal sinuses (Commins et al., 1998). When the orbital bone and nasal cavity are involved, the individuals may develop exophthalmos, visual acuity loss, bulbar displacement and nasal obstruction (Commins et al., 1998; Sun et al., 2007).

Radiographically, the appearances vary with the stage of development of the lesion. Initially there is a well-demarcated radiolucent area when compared to the surrounding bone. As the lesion matures, varying amounts of calcified tissue are deposited, and opaque foci may be seen (Regezi et al., 2000; Soames and Southam, 
2005). In late stages, radiopaque patches coalesce to form a densely radiopaque mass with or without a radiolucent periphery (Whaites, 2007).

Microscopically, an ossifying fibroma is composed of a fibroblastic stroma in which there is new bone formation. Because there is considerable histologic overlap with other fibro-osseous lesions, as well as with odontogenic tumours, osteomyelitis and some osteosarcomas, diagnosis from histological features alone can be difficult (Regezi et al., 2000).

Although the causes of this tumour remain unknown, inflammation secondary to either infections or trauma has been proposed as a causative agent (Barberi et al., 2003; Colard et al., 2008).

Regarding treatment, complete surgical resection is recommended to prevent recurrence (Commins et al., 1998; Su et al., 1997a).

Some exceptional variants, juvenile (aggressive) ossifying fibromas, affect children and adolescents under 15 years of age, exhibit rapid growth and a high recurrence rate (MacDonald-Jankowski, 2004; Sun et al., 2007). The juvenile variants arise outside the tooth-bearing areas, either in the jaws or the craniofacial bones (Speight and Carlos, 2006).

The present case exhibited many of the morphological and radiographic features of an intermediate stage of ossifying fibroma of the right maxilla. In figures 1, 2, 3 and 4, a round, hard, osseous tumour mass invaded the right maxillary sinus. The tumour communicated with the empty socket of the first right maxillary molar. Here it could be postulated that in life, sooner or later, this tooth would be loosened. Radiograph (Figure 5) shows a well-circumscribed radiolucent area when compared to surrounding bone, with internal radiopaque calcified patches. 
The presence of a similar but smaller depression in the same region of the left maxillary bone may correspond to the beginning of a similar lesion affecting also the left maxilla. Although rare, bilateral ossifying fibroma of the maxillary sinus has been previously reported (Barberi et al., 2003).

It is true that the site of predilection is the mandible in around $70 \%$ of cases, but in a large study including 316 cases of benign fibro-osseous lesions of the jaws, a significant percentage (22\%) of ossifying fibromas was found in the molar region of the maxilla (Su et al., 1997b). Besides, there is a great similarity between this case and the palaeopathological diagnose of a right maxilla's cemento-ossifying fibroma recently made by Colard et al. for an individual from the Merovingian period $\left(6^{\text {th }}-7^{\text {th }}\right.$ century AD) (Colard et al., 2008).

\section{Fibrous dysplasia}

For a long time an ossifying fibroma was regarded as a form of localised dysplasia. Fibrous dysplasia is a slow progressive disorder where normal bone is replaced by fibrous tissue and immature woven bone. Similarly, it is more common in females than in males. In contrast, this idiopathic benign condition usually presents in the first two decades of life. The maxilla is most commonly affected, although involvement of the ethmoid and sphenoid tissues can occur (Commins et al., 1998). The radiological appearances of fibrous dysplasia, in contrast to ossifying fibromas, are poorly defined and more radiopaque (MacDonal-Jankowski, 2004). Furthermore, Petrikowski and co-authors (1995) suggested that alteration of the lamina dura to the abnormal bone pattern, and narrowing of the periodontal ligament space are distinguishing features. This may account for the fusiform expansion of fibrous 
dysplasia of the affected bone. Thus the age prevalence (between 20 and 40 years), the round or oval shape and the radiological appearances (well-defined) of the ossifying fibroma make distinction from fibrous dysplasia possible (MacDonal-Jankowski, 2004).

\section{Focal cemento-osseous dysplasia}

Occasionally it may be difficult to distinguish focal cemento-osseous dysplasia, from a conventional ossifying fibroma. Both present as well-circumscribed lesions of variable radiopacity in the tooth-bearing areas (Speight and Carlos, 2006). Focal cemento-osseous dysplasia however is smaller, rarely exceeding $2 \mathrm{~cm}$ in diameter, and may often be associated with a previous tooth extraction site (Speight and Carlos, 2006; Su et al., 1997b). Besides, focal cemento-osseous dysplasia usually blends with the adjacent bone, whereas ossifying fibromas tend to shell out (Speight and Carlos, 2006). Therefore, focal cemento-osseous dysplasia was eliminated.

\section{Conclusions}

We are quite sensitive to the fact that differential diagnosis in osteological materials is limited due to the absence of clinical diagnostic attributes (Ortner, 2003). We are also aware of the importance of performing a histological analysis of the lesion to give a more confident diagnosis. Even so, the macroscopic and radiological features of the tumour, as well as the extraordinary similarity with another recently reported case from the Merovingian period $\left(6^{\text {th }}-7^{\text {th }}\right.$ century AD) (Colard et al., 2008) lead us to diagnose it as a probable ossifying fibroma. Following a study of the clinical literature, 
we imagine that, after one asymptomatic initial period, this individual may have presented facial signs associated with the expansion of the tumour which occupied the right maxillary sinus. If left undisturbed, this tumour would have led to various ophthalmologic, respiratory and dental problems as well as malocclusion.

This appears to be the earliest reported case of this condition in the osteoarchaeological literature, and adds to the very few palaeopathological case descriptions available for ossifying fibroma (Colard et al., 2008; Sawyer et al., 1990). Two other unusual benign tumours in skulls have been described by Strouhal et al. (1996) but those lesions were only destructive and not ossifying.

\section{Acknowledgements}

The authors would like to thank Rui Marques, Rui Boaventura, the Centro de Investigação em Antropologia e Saúde, and the Museu Municipal de Sesimbra. The authors are also grateful to the Serviço de Radiologia dos Hospitais da Universidade de Coimbra for producing the radiographs of the maxilla.

\section{References}

Aufderheide AC, Rodríguez-Martín C. 1998. The Cambridge encyclopedia of human paleopathology. Cambridge University Press: Cambridge. 
Barberi A, Cappabianca S, Colella G. 2003. Bilateral cemento-ossifying fibroma of the maxillary sinus. British Journal of Radiology 76: 279-280. DOI: $10.1259 / \mathrm{bjr} / 15132905$

Cardoso JL. 1992. A Lapa do Bugio. Setúbal Arqueológica IX-X: 89-225.

Clarke NG and Hirsch RS. 1991. Physiological, pulpal, and periodontal factors influencing alveolar bone. In Advances in Dental Anthropology, Kelley MA, Larsen CS (eds). Wiley-Liss: New York; 241-266.

Colard T, Gabart N, Blondiaux J. 2007. A paleopathological case of a right maxilla's cemento-ossifying fibroma. Int $J$ Osteoarchaeol 18: 195-201. DOI: 10.1002/oa.936

Commins DJ, Tolley NS, Milford CA. 1998. Fibrous dysplasia and ossifying fibroma of the paranasal sinuses. The Journal of Laryngology and Otology 112: 964968.

Dias GJ, Prasad K, Santos AL. 2007. Pathogenesis of apical periodontal cysts: guidelines for diagnosis in paleopathology. Int J Osteoarchaeol 17: 619-626. DOI: 10.1002/oa.902

Dias G, Tayles N. 1997. 'Abscess cavity' - a misnomer. Int J Osteoarchaeol 7: $548-554$. 
Hillson S. 1996. Dental Anthropology. Cambridge University Press: Cambridge.

Isidoro AF. 1964. Estudo do espólio antropológico da gruta neo-eneolítica do Bugio (Sesimbra). Trabalhos de Antropologia e Etnologia 19 (3/4): 221-282.

Kerr NW. 1988. A method of assessing periodontal status in archaeologically derived skeletal material. J Paleopathol 2(2): 67-78.

Kerr NW. 1989. The periodontal status of a Scottish Mediaeval cohort. $J$ Paleopathol 2(3): 119-128.

MacDonald-Jankowski DS. 2004. Fibro-osseous lesions of the face and jaws. Clinical Radiology 59: 11-25. DOI: 10.1016/j.crad.2003.07.003

Masset C. 1982. Estimation de l'âge au décès par les sutures crâniennes. Thèse de Doctorat. Université Paris VII: Paris.

Monteiro R, Cunha Serrão E. 1959. Estação Isabel, Necrópole pré-histórica da Azóia. Actas e Memórias do I Congresso Nacional de Arqueologia I: 407-429.

Monteiro R, Zbyszewski G, Veiga Ferreira O. 1971. Nota preliminar sobre a Lapa pré-histórica do Bugio (Azóia - Sesimbra). In Actas do II Congresso Nacional de Arqueologia. Ministério da Educação Nacional: Coimbra; 107-120. 
Ortner DJ. 2003. Background data in paleopathology. In Identification of pathological conditions in human skeletal remains, Ortner DJ (ed.). Academic Press: San Diego; 37-44.

Petrikowski CG, Pharoah MJ, Lee L, Grace MGA. 1995. Radiographic differentiation of osteogenic sarcoma, osteomyelitis and fibrous dysplasia of the jaws. Oral Surg Oral Med Oral Pathol Oral Radiol Endod 80: 744-750.

Regezi JA, Sciubba JJ, Pogrel MA. 2000. Atlas of oral and maxillofacial pathology. W. B. Saunders Company: Philadelphia.

Sawyer DR, Wood NK, Allison MJ. 1990. An ancient 'tumour' from preColumbian Chile. Journal of Craniomaxillofacial Surgery 18: 136-138.

Shafer WG, Hine MK, Levy BM. 1983. A textbook of oral pathology. W. B. Saunders Company: Philadelphia.

Silva AM. 2002. Antropologia Funerária e Paleobiologia das populações portuguesas (litorais) do Neolítico Final/Calcolítico. $\mathrm{PhD}$ dissertation. Universidade de Coimbra: Coimbra.

Soames JV and Southam, JC. 2005. Oral pathology. $4^{\text {th }}$ edn. Oxford University Press: Oxford. 
Speight PM and Carlos R. 2006. Maxillofacial fibro-osseous lesions. Current Diagnostic Pathology 12: 1-10. DOI: 10.1016/j.cdip.2005.10.002

Strouhal E, Vhynánek L, Horáčková L, Benešová L, Němečková A. 1996. Twounusual benign tumours in skulls from the ossuary at Krrtiny (Czech Republic). Int J Osteoarchaeol 6: 289-299.

Su L, Weathers DR, Waldron CA. 1997a. Distinguishing bfeatures of focal cemento-osseous dysplasia and cemento-ossifying fibromas. II. A clinical and radiologic spectrum of 316 cases. Oral Surg Oral Med Oral Pathol Oral Radiol Endod 84: $540-549$.

Su L, Weathers DR, Waldron CA. 1997b. Distinguishing features of focal cemento-osseous dysplasia and cemento-ossifying fibromas. II. A clinical and radiologic spectrum of 316 cases. Oral Surg Oral Med Oral Pathol Oral Radiol Endod 84: $540-549$.

Sun G, Chen X, Tang E, Li Z, Li J. 2007. Juvenile ossifying fibroma of the maxilla. Int J Oral Maxillofac Surg 36: 82-85. DOI: 10.1016/j.ijom.2006.06.024

Whaites E. 2007. Dental radiography and radiology. $4^{\text {th }}$ edn. Churchill Livingstone Elsevier: Edinburgh. 
Zupi A, Ruggiero AM, Insabato L, Senghore N, Califano L. 2000. Aggressive cemento-ossifying fibroma of the jaws. Oral Oncology 36: 129-133. 